\title{
Microtubular Cytoskeleton of Free Endosperm Nuclei During Division in Wheat
}

\author{
Guo-Wei Tian' ${ }^{1}$, Rui-Lin You ${ }^{1, *}$, Feng-Li Guo ${ }^{2}$ and Xue-Chen Wang ${ }^{2}$ \\ ${ }^{1}$ College of Life Sciences, Peking University, Beijing, 100871, P. R. China \\ ${ }^{2}$ College of Biology Sciences, China Agricultural University, Beijing, 100094, P. R. China
}

Accepted August 25, 1998

\begin{abstract}
Summary Microtubular cytoskeleton of free endosperm nuclei during division in wheat was investigated using immunofluorescence labeling technique and confocal scanning laser microscopy. During interphase, microtubles forming a cage around a free nucleus were observed and the orientations of microtubuls (Mts) paralleled to long axis of the ellipsed-shaped free nucleus. During prophase, the orientation of the perinuclear Mts changes from parallel to long axis of a free nucleus to vertical to it, and subsequently the Mts constituted directly metaphase spindle Mts while the nuclear envelope broke down. Spindle Mts were observed during both metaphase and anaphase. A short lived cell plate was deposited in the just formed phragmoplast at either late anaphase or early telophase, but it disappeared subsequently resulting in the failure of cell wall formation. The perinuclear Mts were reconstructed initiating from the daughter nuclear envelopes at early interphase stage. The results suggested that changes of the Mts orientation during prophase might be associated with the determination of plane of nuclear division and the perinuclear Mts had a role in maintenance of the shape of interphase nuclei in syncytium of wheat endosperm.
\end{abstract}

Key words Triticum aestivum, Endosperm, Free nucleus, Microtubule, Division

Endosperm is a product of double fertilization in angiosperms, i.e., the union of one sperm cell with the egg results in the diploid zygote and the other sperm with polar nuclei or secondary nucleus results in the primary endosperm nucleus from which develops the nutritive tissue. Three general types of endosperm development were recognized (Vijiayraghavan and Prabhakart 1984): i.e. cellular, nuclear and helobial. Endosperm development in cereals is of the nuclear type and especially in wheat, has been studied by several authors (Evers 1970, Mares et al. 1975, 1977, Morrison and O'Brien 1976, Morrison 1978, Fineran et al. 1982, Van Lammeren 1988). But much attention of aforementioned authors was paid to dealing with cellularization of the nuclear type endosperm, which was also studied on other species by some authors (Newcomb and Fowke 1973, Bosnes et al. 1992, Brown et al. 1994), and little dealt with the free nuclear division of it. In spite of lots of literature dealing with the microtubuls (Mts) in division of plant body cells (For review see Gunning 1982, Zhu 1996) and in endosperm cells (Morrison and O'Brien 1976, Jensen 1982, Bajer and Mole-Bajer 1986, Brown et al. 1994), little was known in detail about changes of the microtubular cytoskeleton of free nuclear division in the nuclear type endosperm during its early development, which was only dealt with occasionally in studying on the Mts of endosperm in some species (Van Lammeren 1988, Huang et al. 1990, Webb and Gunning 1991, Brown et al. 1994).

The aim of this research was to reveal changes of Mts during the division of free nuclei in wheat endosperm using immunofluorescence labeling technique and confocal scanning laser microscopy (CSLM). Our results showed that some new features of the changes of Mts existed in the free nuclear division in wheat endosperm.

* To whom correspondence should be adressed. 


\section{Materials and methods}

Plants of spring wheat, Triticum aestivum L, used for this study were cultivated in the field at Peking University, Beijing. Ovaries at 0 to 2 days after pollination (DAP) were collected and divided into two groups for the immunofluorecence microscopy and the Feulgen staining.

\section{Immunofluorecence microscopy}

A modified procedure for immunofluorecence microscopy was conducted below based on the method described by Huang et al. (1993). The ovaries were separated and put in PEMG buffer [50 mM Pipes (piperazine-N,N'-bis[2-ethanesulphonic acid]), 5 mM EGTA (ethylene glycol-bis $[\beta$ aminoethyl ester]-N,N, $\mathrm{N}^{\prime}, \mathrm{N}^{\prime}$-tetraacetic acid), $2 \mathrm{mM} \mathrm{MgSO}_{4}$ and $4 \%$ glycerol, $\mathrm{pH}$ 6.9], in which ovules were dissected and immediately fixed in $4 \%$ paraformaldehyde in PEMG buffer containing $10 \%$ dimethylsulphoxide (DMSO) and $0.1 \%$ Triton X-100 for $1 \mathrm{hr}$ at room temperature, and rinsed in four changes of PEMG buffer without above-mentioned additives. Endosperm were isolated from ovules in PEMG buffer by hand dissection with needles under a dissecting microscope, and subsequently put them in a mixture of $1 \%$ Triton $\mathrm{X}-100$ and $3 \%$ Nodient $\mathrm{P}-40(\mathrm{v} / \mathrm{v}=1: 1)$ in PEMG buffer for $2 \mathrm{hr}$. After three rinses in phosphate buffered saline (PBS) (pH 7.2), the samples were treated with $-20^{\circ} \mathrm{C}$ methanol for $10 \mathrm{~min}$, then rinsed in three 10 min changes of blocking solution (PBS containing 1\% bovine serum albumin). Subsequently samples were incubated in a mouse monoclonal Anti- $\alpha$-tubulin (Sigma) diluted 1:500 in blocking solution at $37^{\circ} \mathrm{C}$ for $2 \mathrm{hr}$. After three rinses in blocking solution the samples were treated with FITC-conjugated sheep anti-mouse IgG (Sigma) diluted $1: 250$ for $1-2 \mathrm{hr}$ at $37^{\circ} \mathrm{C}$. After three rinses in PBS the samples were mounted in anti-fading solution containing a 1:1 ratio of PBS: glycerol to which 3\% n-propyl gallate was added.

Control experiments were conducted as follows: (1) omission of primary antibody, (2) omission of secondary antibody, (3) omission of both antibodies (Huang et al. 1993). All controls showed no tubulin fluorescence. CSLM were conducted using a Bio-Rad MCR-1024 microscope.

\section{Feulgen staining}

In order to show the morphological features of free endosperm nuclei in mitosis clearly, the free nuclear DNA of endosperm was stained with Feulgen technique. The overies were dissected and fixed in acetic-alcohol $(1: 3)$ for $2-3 \mathrm{hr}$ and stored in $70 \%$ alcohol. After rinsing with declining gradient alcohol and then distilled water, the ovules were extracted with the mixture of $1 \%$ Triton $\mathrm{X}-100$ and 5\% DMSO for $2 \mathrm{hr}$ and subsequently rinsed with distilled water for $2 \mathrm{hr}$. The nuclear DNA stained according to Feulgen reaction (Jian 1987). Subsequently, the endosperm were isolated from ovules by hand dissection with needles and dehydrated through an ascending gradient alcohol and clarified with xylol grades and mounted in Canada balsam. Observations and photography were conducted under an Olympus BH-2 research photomicroscopy.

\section{Results}

The processes of double fertilization in wheat were completed within about $10 \mathrm{hr}$ after pollination, in which one of two sperms fused with the central cell to produce a primary endosperm cell (Shen et al. 1983). Subsequently, the free nuclear endosperm was formed by repeated divisions of the primary endosperm nucleus and numerous free nuclei distributed along the periphery of endosperm cytoplasm in which a large central vacuole existed. Cellularization of endosperm initiated from about 3 to 4 DAP (Bennett et al. 1973, Morisson and O'Brien 1976, Van Lammeren 1988). The following described mainly in the changes of Mts in free nuclear division of endosperm at 0 to 2 DAP. 

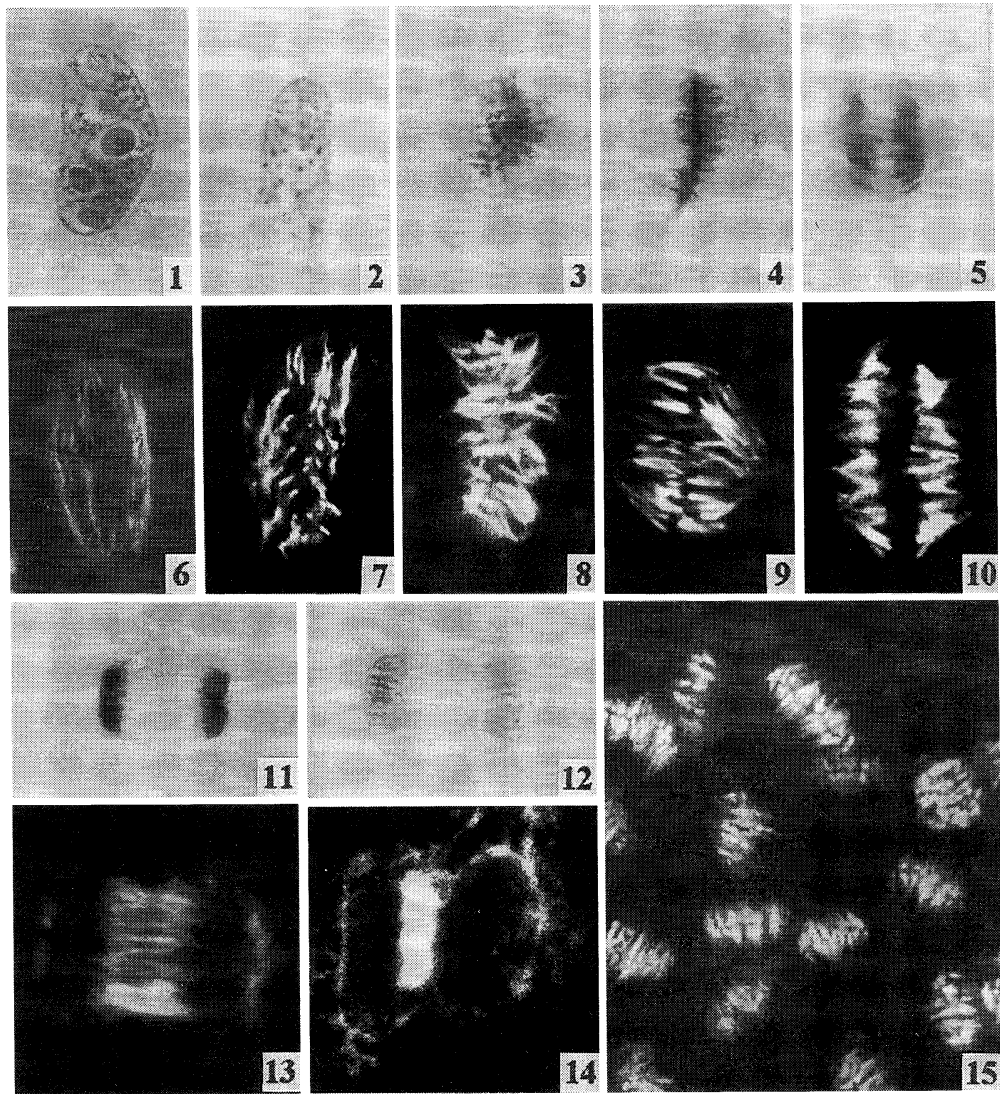

Figs. 1-15. Free endosperm nuclei in wheat. 1-5, 11, 12. Showing various changes of chromosomes at different stages of division with Feulgen staining. 6-10, 13-15. Showing microtubules changes at different stages of division. 1. Interphase $(\times 720)$. 2. Prophase $(\times 720)$. 3. Prometaphase $(\times 720)$. 4. Metaphase $(\times 720)$. 5. Anaphase $(\times 720)$. 6. Interphase $(\times 850)$. 7. Prophase $(\times 850)$. 8. Prometaphase $(\times 850)$. 9. Metaphase $(\times 850)$. 10. Anaphase $(\times 1000)$. 11. Telophase $(\times 720)$. 12. Two daughter nuclei $(\times 720)$.

13. Telophase, showing a slightly dark band in the center of phragmoplast microtubules $(\times 900)$. 14. Two daughter nuclei $(\times 900)$. 15 . Numerous free nuclei in metaphase $(\times 340)$.

During interphase, a free nucleus containing 3 to 5 nucleoli was ellipse- or kidney-shaped and distributed in cytoplasm of endosperm (Fig. 1). Numerous Mts were observed around the free nucleus in interphase, which formed a perinuclear cage in parallel to the long axis of the ellipsedshaped free nucleus (Fig. 6). Neither extensive networks of Mts radiating from the interphase nuclei nor connective Mts between the two free nuclei were observed.

During prophase, the nucleoli of a free nucleus began to disappear while the chromosomes themselves began to appear, which became shorter and thicker and thus more easily visible (Fig. 2). At this time, the orientation of perinuclear Mts changed from parallel to the long axis of a free nucleus to an acute angle with (Fig. 7) and then vertical to it in prometaphase (Fig. 8), resulting in a right angle rotation of the orientation of perinuclear Mts. The changes of orientation of Mts in prophase determined that the free nuclei would divide in a longitudinal plane. At the same time, the perinuclear Mts assembled gradually and became shorter forming thicker arrays (Figs. 7, 8). No typical spindle arrays of Mts formed the same as plant body cells in prophase.

During metaphase, the nuclear membrane began to disappear (Fig. 3) and the spindle began to appear. The centromere of each doublet became attached to a microtubule and migrated to a point midway between the poles. The loose ends of the chromosomes may be oriented randomly, but all 
the centromeres lay exactly in a plane at the "equator" (Fig. 4). The prophase Mts constituted the spindle Mts directly while nuclear envelopes broke down in metaphase (Figs. 9, 15). A dark region in the center of spindle arrays represented the metaphase chromosomes arranged in the equatorial plane. Two broad polar ends of the spindle responded because of the nucleus dividing in a longitudinal plane (Figs. 9, 15).

During anaphase, the duplicated chromosomes of each doublet separated from each another and migrated to the opposite poles (Fig. 5). At this time, the half of spindle Mts separated each other and decreased gradually (Fig. 10), then the phragmoplast Mts appeared in the mid-zone at either late anaphase or early telophase (Fig. 13).

During telophase, the chromosomes reached their poles (Fig. 11) and began to uncoil. New nuclear membrane began to form around the chromosomes (Fig. 12). Phragmoplast arrays emerged in telophase, in which a slightly dark central band existed at early telophase (Fig. 13), showing the formation of a cell plate at this time. Soon after, however, the dark central band disappeared (Fig. 14), showing dissipation of the cell plate in later telophase. But the phragmoplast arrays existed between the daughter nuclei for a longer time (Fig. 14). Perinuclear Mts were deposited gradually on the nuclear envelopes of daughtr nuclei at the same time (Fig. 14). A division cycle of a free nucleus was completed without cytokinesis when the phragmoplast arrays disappeared completely. No distinct Mts was observed in the cytoplasm of free nuclear endosperm during the free nuclear division.

\section{Discussion}

A lot of studies on microtubular cytoskeleton of plant body cells during division using indirect immonofluorescence labeling technique and electron microscopy have revealed a general rule of Mts changes including cyclic changes, that is, orderly from interphase Mts (peripheral and perinuclear Mts) to prophase Mts (preprophase band [PPB] Mts and spindle Mts), metaphase and anaphase Mts (spindle Mts and phragmoplast Mts), telophase Mts (phragmoplast Mts) and the appearance of interphase Mts (for review see Gunning 1982, Zhu 1996). However, there were a few reports on Mts of free endosperm nuclei during division (Fineran et al. 1982, Huang et al. 1990, Webb and Gunning 1991, Brown et al. 1994). It has been known that there are mainly two differences in the changes of Mts between the plant body cells and free endosperm nuclei during division. First, the later had no PPBs, which was also found in the meioses of microsporogenesis (Van Lammeren 1985, Hogan 1987, Traas et al. 1989) and megasporogenesis (Bednara et al. 1988, Willemse and Van Lammeren 1988), and in the divisions of protoplast (Foeke and Gamborg 1980), moss protonema (Jensen 1981), formation of vegetative and generative cells (Sanger and Jackson 1971), and generative cells in pollen (Cass and Karas 1975, Van Lammeren et al. 1985). Second, the phragmoplast Mts dissipated without cell walls formation during free nuclear division (Huang et al. 1990, Webb and Gunning 1991, Brown et al. 1994). Similar phenomena on the above-mentioned two Mts behaviors of Mts were observed in free nuclear division of endosperm of wheat in this paper. Apart from these, some new features of Mts changes that other authors had not reported were also observed during free nuclear division in our data. First, the orientation of perinuclear Mts paralleled to the long axis of an ellipsed-shaped free nucleus in interphase. Second, the orientation of perinuclear Mts rotated a right angle from parallel to the long axis of a free nucleus to vertical to it during prophase, and the Mts could directly constitute metaphase spindle Mts. Third, there was an appearance and dissipation of the cell plate in telophase. Further research is required if these phenomena also exist in free nuclear division of the endosperm in other species. The cause of different results between our and others' studies was not well known, it might be due to different plants used or different procedures of investigation.

The phenomenon of perinuclear Mts existing in interphase nuclei in free nuclear endosperm has been reported in some plants including Triticum aestivum (Van Lammeren 1988), Arabidopsis 
thaliana (Webb and Gunning 1991), and Hordeum vulgare (Brown et al. 1994), and it was also found in many other multinucleate cells (e.g., Woodcock 1971, LaClaire 1987). All above-mentioned perinuclear Mts were extensive networks of Mts radiating from nuclei, which were believed to contribute to the correct spacing of the nuclei in coenocytic phase (Van Lammeren 1988) and contribute to organizing the cytoplasm into discrete units and determining the placement of walls in cellularization of endosperm (Brown et al. 1994). They were different from that in our study on interphase Mts behaviors of free endosperm nuclei in wheat, of which the orientation was parallel to the long axes of ellipsed-shaped free endosperm nuclei. It has been known that the microtubular control of cells in shape existed in some plant cells, such as the zoospores of Pediastrum borynum (Marchant 1979) and the generative cell of Haemanthus kahterinae (Sanger and Jackson 1971), and some animal cells, such as the red blood cells (for review see Behnke 1970, Dustin 1984) and the insect egg cells (Tucker and Meats 1976). So the perinuclear Mts of wheat endosperm may have a role in the maintenance of the shape of ellipsed-shaped free nuclei of interphase in our study. Similar function of Mts was found in spermatogenesis of animals (Kessel 1966, McIntosh and Porter 1967, for review see Dustin 1984).

The plane of division of free endosperm nuclei in wheat did not follow the usual laws of cell division. They divided vertically, in the longitudinal plane, thus contravening Errera's law, which asserted that a cell would divide by a wall of minimal area (Cutter 1978, Lloyd and Barlow 1982). Similar phenomena existed in the division of fusiform initials of cambium in plants (Cutter 1978). The orientation of Mts of prophase and metaphase during division were closely associated with the dividing plane in plant cells. Therefore, the changes of microtubular orientation in free nuclear division of wheat endosperm in prophase determined the nuclear dividing plane, in a longitudinal plane, of which function was similar to that of PPBs which anticipates the plane of division in plant body cells (for review see Gunning 1982, Gunning and Hardham 1982, Mineyuki and Gunning 1990, Zhu 1996). Based on above-mentioned facts, the nucleus may be considered as a polar structure, at least it has a physiological polarity. What determined the changes of Mts orientation of the free nuclei in prophase of division in wheat endosperm is still not well known, it is an interesting and important question.

There was an appearance and then disappearance of a cell plate formation at late anaphase and early telophase in free nuclear division of wheat endosperm. Similar result was found in Fineran's $e t$ al. (1982) study on ultrastructure of wheat endosperm, in which authors believed typical phragmoplasts appearing between the free nuclear division and cytokinesis had been observed in the formation of the first anticlinal walls during cellularization. The cause and mechanism of dissipation of the cell plate at its late developmental stage are not known at present, which can help us well understand the origin of the different endosperm types.

\section{Acknowledgments}

The authors would like to thank Dr. Miao Long, College of Biology Sciences, China Agricultural University, for his technical assistance with the confocal microscope facility.

\section{References}

Bajer, A. S. and Mole-Bajer, J. 1986. Reorganization of microtubules in endosperm cells and cell fragments of the higher plant Haemanthus in vivo. J. Cell Biol. 102: 263-281.

Bednara, J., Van Lammeren, A. A. W. and Willemse, M. T. M. 1988, Microtubular configurations during meiosis and megasporogenesis in Gasteria verrucosa and Chamaenerion angustifolium. Sex. Plant Reprod. 1: 164-172.

Behnke, O. 1970. Microtubules in disk-shaped blood cells. Intern. Rev. Esp. Pathol. 9: 1-92.

Bennett, M. D., Rao, M. K., Smith, J. B. and Bayliss, M. W. 1973. Cell development in the anther, the ovule, and the younng seed of Triticum aestivum L. var. Chinese spring. Philos. Trans. R. Soc. London, ser. B, 266: 39-81. 
Bosnes, M., Widemann, F. and Olsen, O.-A. 1992. Endosperm differentiation in barley wild-type and SEX-mutants. Plant J. 2: $661-674$.

Brown, R. C., Lemmon, B. E. and Olsen. O.-A. 1994. Endosperm development in barley: microtubule involvement in the morphogenesis pathway. Plant Cell 6: 1241-1252.

Cass, D. D. and Karas, I. 1975. Development of sperm cells in barley. Can. J. Bot. 53: 1051-1062.

Cutter, E. G. (ed). 1978. Plant Anatomy, Pert 1 Cells and Tissues (2nd Ed.). pp. 242-259, Edward Arnold (Publishers) Ltd., London.

Dustin, P. 1984. Cell shapes. In: P. Dustin (ed.), “Microtubules (second totally revised edition)”, pp. 234-266, Springer-Verlag, Berlin Heidelberg, New York, Tokyo.

Evers, A. D. 1970. Development of the endosperm of wheat. Ann Bot. 34: 547-555.

Fineran, B. A., Wild, D. J. C. and Ingerfeld, N. 1982. Initial wall formation in the endosperm of wheat, Triticum aestivum: a reevaluation. Can. J. Bot. 60: 1776-1795.

Fowke, L. C. and Gamborg, A. R. 1980. Applications of protoplasts to study of plant cells. Int. Rev. Cytol. 68: 10-51.

Gunning, B. E. S. 1982. The cytokinetic apparatus: its development and spatial regulation. In: C. W. Lloyd (ed.), "The Cytoskeleton in Plant Growth and Development", pp. 229-292, Academic Press, London.

— and Hardham, A. R. 1982. Microtubules. Ann. Rev. Plant Physiol. 33: 651-698.

Hogan, C. L. 1987. Microtubule patterns during meiosis in two higher plant species. Protoplasma 138: 126-136.

Huang, B.-Q., Pierson, E. S., Russell, S. D., Tiezzi, A. and Cresti, M. 1993. Cytoskeleton organization and modification during pollen tube arrival, gamete delivery and fertilization in plumbago zeylanica. Zygote 1: 143-154.

$\hookrightarrow$ Russell, S. D., Strout, G. W. and Mao, L.-J. 1990. Organization of isolated embryo sacs and eggs of Plumbago zeylanica (Plumgaginaceae) before and after fertilization. Amer. J. Bot. 77: 1401-1410.

Jensen, C. G. 1982. Dynamics of spindle microtubule organization: kinetochore fiber microtubules of plant endosperm. J. Cell Biol. 92: 540-559.

Jensen, L. C. W. 1981. Division growth and branch formation in moss protonema Physcomitivum turbinatum studies on sequential cytological changes in living cells. Protoplasma 107: 301-308.

Jian, L.-C. 1987. Methods in cytochemistry. In: J.-S. Shun and Y.-Q. Qian (eds.), "Methods in Plant Cytology", pp. 133-183, Science Press, Beijing.

Kessel, R. G. 1966. The association between microtubules and nuclei during spermatogenesis in the dragonfly. J. Ultrastruct Res. 16: 293-304.

LaClaire, J. W. H. 1987. Microtubule cytoskeleton in intact and wounded coenocytic green algae. Planta 171: 30-42.

Lloyd, C. W. and Barlow, P. W. 1982. The co-ordination of cell division and elongation: the role of the cytoskeleton. In: C. W. Lloyd (ed.), "The Cytoskeleton in Plant Growth and Development", pp. 203-228, Academic Press, London.

Marchant, H. J. 1979. Microtubular determination of cell shape during colony formation by the alga Pediastrum. Protoplasma 98: 1-14.

Mares, D. J., Norstog, K. and Stone, B. A. 1975. Early stages in the development of wheat endosperm. I. the changes from free nuclear to cellular endosperm. Aust. J. Bot. 23: 311-326.

-, Stone, B. A., Jeffery, C. and Norstog, K. 1977. Early stages in stages in development. II. ultrastructural observations on cell wall formation. Aust. J. Bot. 25: 599-613.

McIntosh, J. R. and Porter, K. P. 1967. Microtubules in the sprmatids of the dometic fowl. J. Cell Biol. 35: $153-173$.

Mineyuki, Y. and Gunning, B. E. S. 1990. A role for preprophase bases of microtubules in maturation of new cell walls and a general proposal on the function of preprophase band diets in cell division in higher plants. J. Cell Sci. 97: 527537.

Morrison, I. N. 1978. Initial cellularization and differentiation of the aleurone cells in the ventral region of the developing wheat grain. Planta 140: 19-30.

— and O'Brien, T. P. 1976. Cytokinesis in the developing wheat grain; division with and without phragmoplast. Planta 130: 57-67.

Newcomb, W. and Fowke, L. C. 1973. The fine structure of the changes from the free-nuclear to cellular condition in the endosperm of chickweed Stellaria media. Bot. Gaz. 134: 236-242.

Sanger, J. M. and Jackson, W. T. 1971. Fine structure study of pollen development in Haemanthus katherinae Baker. K. formation of vegetative and generative cells. J. Cell Sci. 8: 289-301.

Shen, J.-H., Wang, P., Li, H.-R. and Yin, H. 1983. On the process of fertilization in spring wheat and its duration of each stages. Acta Agronomica Sinica. 9: 79-83.

Traas, J. A., Bungain, S. and Dumas De Vault, R. 1989. The organization of the cytoskeleton during meiosis in eggplant (Solanum melongena (L.)): meiotic division. J. Cell Sci. 92: 541-550.

Tucker, J. B. and Meats, M. 1976. Microtubules and control of insect egg shape. J. Cell Sci. 71: 207-212.

Van Lammeren, A. A. M. 1988. Structure and function of the microtubuar cytoskeleton during endosperm development in wheat: an immunofluorescence study. Protoplasma 146: 18-27.

`Keijzer, M. C. J., Willemse, M. T. M. and Kieft, H. 1985. Structure and function of the microtubular cytoskeleton during 
pollen development on Gasteria verrucosa (Mill) H. Duval. Planta 165: 1-11.

Vijayraphavan, M. R. and Prabhakart, K. 1984. The endosperm, In: B. M. Johri (ed.), "Embryology of Angiosperms", pp. 319-376, Springer-Verlag, Berlin.

Webb, M. C. and Gunning, B. E. S. 1991. The microtubular cytoskeleton during development of the zygote, proembryo and free-nuclear endosperm in Aradopsis thaliana (L.) Heynh. Planta 184: 187-195.

Willemse, M. T. M. and Van Lammeren, A. A. M. 1988. Structure and function of the microtubular cytoskeleton during megasporogenesis and embryo sac development in Gasteria verrucosa (Mill.) H. Duval. Sex. Plant Reprod. 1: 74 82.

Woodcock, C. L. F. 1971. The anchoring of nuclei by cytoplasmic microtubules in Acetabularia. J. Cell Sci. 8: 611-621.

Zhu, C. 1996. Cycles of microtubules and microfilaments in plant body cells. In: Xu, Shi-Xiong (S. Y. Zee) and Zhu, C. (eds.) Cytoskeleton in Plant Cells, pp. 60-83, Science Press, Beijing. 